\title{
KINERJA RANTAI PASOK PRODUK SAYURAN DI KOTA BOGOR
}

\section{SUPPLY CHAIN PERFORMANCE OF VEGETABLE PRODUCTS IN BOGOR CITY}

\author{
Himmatul Miftah", Arti Yusdiarti, Dean Riza Rivanda
}

\author{
Jurusan Agribisnis, Fakultas Pertanian Universitas Djuanda Bogor \\ Jl. Tol Ciawi No. 1 PO Box 35 Ciawi Bogor 16720, Telepon/Fax: 0251-8240773/8240985 \\ *Corresponding email: dinanrohima@gmail.com \\ (Diterima 22-09-2018; Disetujui 29-12-2018)
}

\begin{abstract}
ABSTRAK
Peningkatan jumlah penduduk, tingkat komsumsi sayuran dan tren gaya hidup sehat membuka peluang bagi pemasaran sayur-sayuran. Peluang ini perlu dimanfaatkan sehingga menguntungkan petani sayuran. Keuntungan dapat dicapai melalui pemilihan rantai pasok yang berpihak kepada petani melalui model pengembangan rantai pasok sayuran di Kota Bogor. Tujuan penelitian adalah menganalisis komponen sistem rantai pasok yang dilakukan petani sayuran ke pasar tradisional ditinjau dari kinerja rantai pasokannya. Metode pengumpulan data dengan cara survei dan observasi lapangan. Responden utama adalah petani produsen sayur yang menjual ke pasar tradisionil, baik secara langsung atau melalui perantara. Responden dipilih secara purposive sebanyak tiga responden untuk jenis pasar Bogor dan pasar Jambu Dua. Responden lainnya adalah pelaku tataniaga dan petani yang dirunut dengan metode snowball sampling sampai ke petani produsen yang jumlahnya sesuai jenis rantai pasok yang ada. Data dianalisis untuk menentukan performance rantai pasok melalui metode SCOR. Hasil penelitian menunjukkan bahwa produsen sayuran daun berasal dari lokasi lahan petani yang berdekatan dengan kota Bogor. Semua jenis sayuran yang diteliti dalam distribusinya melalui proses ekualisasi. Performance rantai pasok sayuran tradisional belum terintegrasi keterkaitan erat antara keinginan konsumen dengan produsen/petani, baik dalam perencanaan (plan), pengadaan (source), produksi (make), distribusi (deliver) dan pengembalian (return) serta tindakan (enable). belum optimalnya performa/kinerja rantai pasok sayuran di pasar tradisional ditinjau dari aspek reliabilitas, responsivitas, fleksibilitas, biaya dan manajemen aset rantai pasok.
\end{abstract}

Kata kunci: Kinerja rantai pasok sayuran, margin, farmershare

\begin{abstract}
Increasing in population, vegetable consumption levels and healthy lifestyle offer a big opportunities for the vegetables marketing. These opportunities need to be utilized to bring benefit for vegetable farmers. Profits can be achieved through the selection of a supply chain that favors farmers through a development model of vegetable supply chain in Bogor City.The purpose of this research is to analyze the components of supply chain system by vegetable farmers to traditional markets in terms of their supply chain performance. The vegetables analyzed were spinach, potato, tomato, and onion. Data obtained by survey and observation. The main respondents are farmers vegetable producers who sell to traditional markets, either directly or through intermediaries. Three retailers as respondents were chosen purposively in each vegetable at Bogor and Jambu Dua market. Other respondents are marketers and farmers who were chosen by the retailers (snowball sampling method). Data were analyzed to determine the supply chain performance through SCOR method. The results showed that the producers spinach and tomato supplied from the farmers nearby to Bogor City. While other vegetables like onions and potatoes were supplied from farmers in West Java and mid Java. All vegetables studied in their distribution through equalization process. Performance of traditional vegetable supply chain has not yet integrated consumer expectation and producers/ farmers in planning, procurement, production, distribution, return, and action. This unoptimal performance of vegetable supply chain in traditional markets
\end{abstract}


reviewed from supply chain reliability, responsiveness, flexibility, and assets management of supply chain.

Keywords: Performance of vegetable supply chain, margin, farmershare

\section{PENDAHULUAN}

Jumlah penduduk Indonesia yang semakin bertambah mendorong kebutuhan barang pangan yang semakin banyak pula termasuk konsumsi sayuran. Peningkatan jumlah penduduk dan jumlahnya tingkat komsumsi sayuran membuka peluang bagi pemasaran sayursayuran di pasar domestik. Selain peningkatan jumlah penduduk, konsumsi sayuran per kapita juga masih relatif rendah sehingga peluang pasar sayuran semakin terbuka.

Kondisi ini telah membuka peluang yang dimanfaatkan petani untuk memperoleh pasar yang baik bagi konsumen, yang memberikan kesempatan untuk dapat mendatangkan keuntungan guna meningkatkan kapasitas usahatani dan kehidupannya. Kota Bogor merupakan kota penyangga ibukota yang kian lama semakin padat penduduknya. Pertambahan penduduk disertai dengan meningkatnya daya beli masyarakatnya memberikan dampak pada tuntutan pola konsumsinya. Tuntutan pada konsumsi produk yang berkualitas termasuk produk sayuran dan meningkatnya berbagai jenis produk sayuran karena tuntutan dan selera konsumen mendorong tumbuhnya pasar modern yang ada di kota Bogor. Semakin meningkatnya harga dari berbagai jenis sayuran yang telah dibeli apakah telah diikuti pula oleh meningkatnya penerimaan petani sayuran sehingga meningkatkan pendapatannya? Permasalahan ini perlu diteliti. Hasil penelitian dapat direkomendasikan guna menyusun model pengembangan rantai pasok yang ideal dan berpihak pada kesejahteraan petani.

\section{METODE PENELITIAN}

Jenis penelitian dalam kegiatan ini adalah explorative and developmental research. Penelitian eksploratif dilaksanakan untuk memperoleh gambaran/ pemetaan mengenai profil petani dan kegiatan rantai pasok sayur yang dijual ke kota Bogor, dan inventarisasi kegiatan produktif yang dilaksanakan dalam distribusi sayur. Eksploratif yang dimaksud di sini adalah mencari dan menggali informasi yang ada dan berkembang di masyarakat dengan menggali kenyataan sosial dan ekonomi yang ada dan mengkaitkannya dengan 
budaya yang dimiliki oleh anggota masyarakat.

Developmental research dilaksanakan guna menerapkan model pengembangan rantai pasok sayur dalam meningkatkan pendapatan petani sehingga berkontribusi pada upaya pengentasan kemiskinan.

Lokasi penelitian dipusatkan di wilayah tujuan pemasaran sayur di kota Bogor. Lokasi kota Bogor dipilih karena berkembangnya lokasi pemasaran sayur, baik yang dilaksanakan melalui pasar tradisional maupun pasar modern. Lokasi utama di pasar tradisional dan pasar modern di kota Bogor, sedangkan para pelaku tataniaga dirunut berdasarkan lokasi para pedagang dan pemasok berdomisili. Lokasi pemasok dapat berada di lokasi sekitar wilayah Kota dan Kabupaten Bogor, bahkan dapat pula berasal dari luar kota atau luar kabupaten diantaranya Cipanas Cianjur, Kabupaten Sukabumi atau Pangalengan dan Lembang di wilayah Bandung sebagai sentra produk sayuran.

Berdasarkan pertimbangan data identifikasi rantai pasok ditentukan dua pasar tradisional dan dua pasar modern di Kota Bogor.

Penelitian dilaksanakan selama dua tahun. Tahun pertama telah dimulai pada bulan April-Nopember 2017. Sedangkan tahun kedua dilaksanakan mulai bulan April-Nopember 2018.

Responden utama dalam penelitian ini adalah pedagang pengecer yang membeli sayur di pasar tradisional dan pengelola pasar modern yang berperan sebagai pengecer. Jumlah responden ditentukan sebanyak tiga responden pengecer di pasar tradisional dan tiga pasar modern yang dipilih secara acak. Responden lainnya adalah para pelaku tataniaga yang dirunut informasinya dengan menggunakan metode snowball sampling. Responden tataniaga dirunut sampai ketemu petani yang memproduksi sayuran. Jumlah petani ditentukan sebanyak lima orang yang jumlah keseluruhannya disesuaikan dengan banyaknya jenis rantai pasok yang ada.

Data dikumpulkan dengan menggunakan teknik wawancara langsung dengan menggunakan kuesioner dan dengan melakukan observasi di lapangan. Selain pengumpulan data primer, juga dikumpulkan data dan informasi dan karakteristik eksternal seperti dukungan dari pemerintah, pelaku tataniaga lainnya yang memperlancar proses tataniaga serta lembaga yang mempunyai keterkaitan aktivitas ekonomi lainnya. 


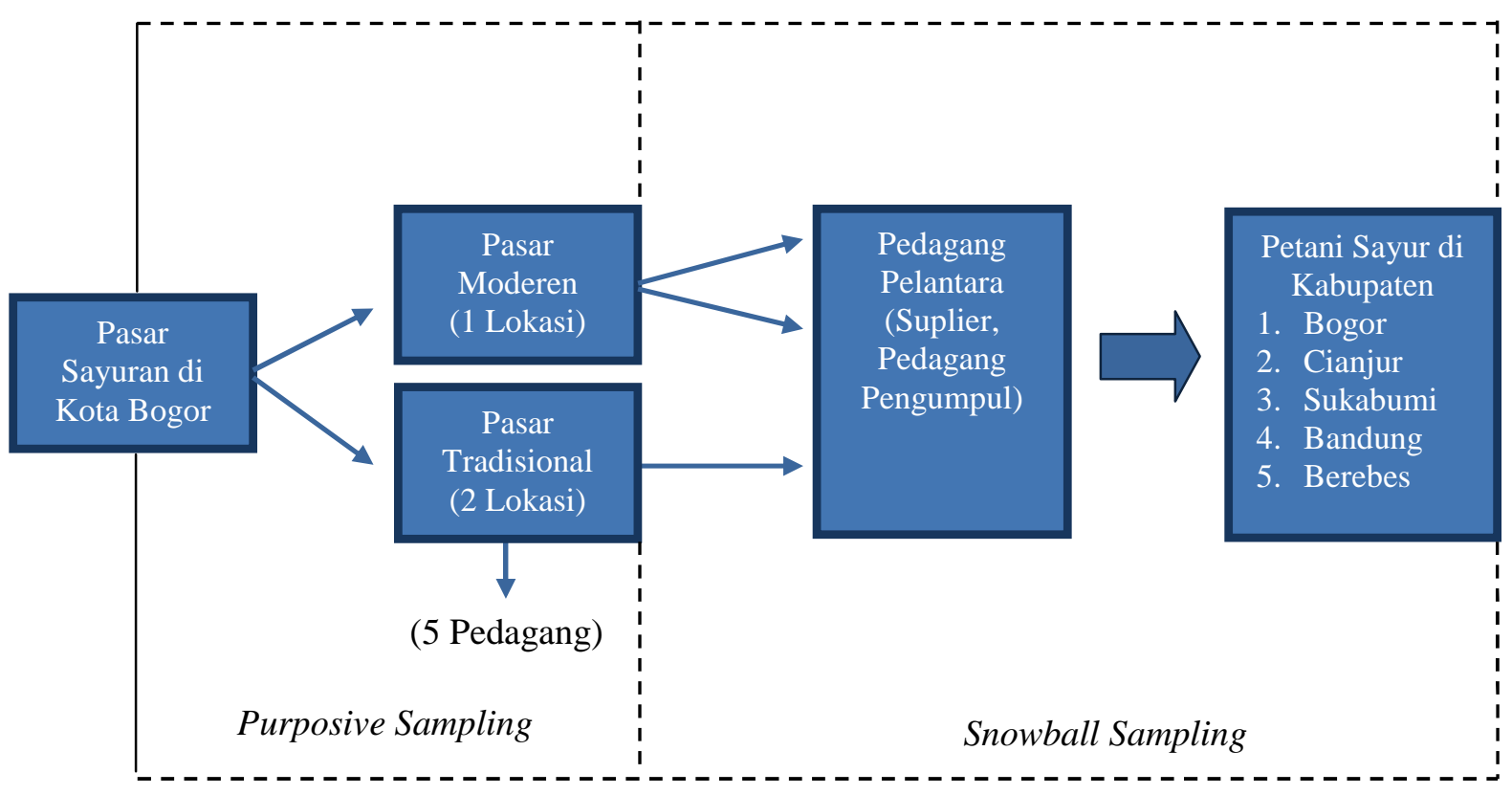

\section{Gambar 1. Kerangka Sampling}

Data yang telah dikumpulkan diolah secara kuantitatif, lalu ditampilkan dalam bentuk tabel dan grafik. Selanjutnya dibuat matrik pemetaan pemasaran yang menggambarkan proses tataniaga yang dilaksanakan dalam mengalirkan produk dari lahan pertanian ke konsumen akhir. Data kuantitatif dianalisis dalam komponen sistem, subsistem dan sub-sub sistem sehingga dapat diketahui hubungan keterkaitannya secara terintegrasi. Hubungan antar komponen di dalam sistem didekati dengan persamaan matematis antar variabel. Data kuantitatif dihitung untuk menentukan besarnya market share dan margin tataniaga. Indikator performance efisiensi tataniaga dihitung secara matematik dan hasilnya dibandingkan dengan standar indikator efisiensi rantai pasok di Asia yang meliputi empat indikator utama.

Perhitungan margin pemasaran menggunakan rumus (Mubyarto, 1989):

$$
\mathrm{Mm}=\mathrm{Pe}-\mathrm{Pf}
$$

Keterangan:

$\mathrm{Mm}=$ Margin pemasaran di tingkat petani

$\mathrm{Pe}=$ Harga di tingkat kelembagaan pemasaran tujuan pemasaran dari petani

Pf $=$ Harga di tingkat petani

Perhitungan margin pemasaran menggunakan persamaan berikut:

$$
\mathrm{Mm}=\mathrm{Ci}+\pi \mathrm{i}
$$

Keterangan:

$\mathrm{Mm}=$ Margin pemasaran

$\mathrm{Ci}=$ Biaya pemasaran

$\pi \mathrm{i}=$ Keuntungan

Perhitungan Farmer share menggunakan persamaan berikut:

Farmer share $=\mathrm{Pf} / \mathrm{Pe} \times 100 \%$ 
Keterangan:

$$
\begin{aligned}
\mathrm{Pf}= & \text { Harga di tingkat petani } \\
\mathrm{Pe}= & \text { Harga di tingkat kelembagaan } \\
& \begin{aligned}
\text { pemasaran tujuan pemasaran } \\
\text { dari petani }
\end{aligned}
\end{aligned}
$$

Pembuatan model rantai pasok dilakukan dengan cara menyusun skenario saluran pemasaran yang paling efisien dan paling banyak memberikan kontribusi keuntungan kepada petani. Evaluasi rantai pasok yang direkomendasikan dilakukan dengan menggunakan metode SCOR (Supply Chain Operational Reference). Metode ini menilai kinerja rantai pasok dari dua perspektif, yaitu internal business process dan customer. Terdapat lima proses utama supply chain, yaitu perencanaan (Plan), pengadaan (Source), pembuatan (Make), pengiriman (Deliver), dan pengembalian (Return).

\section{HASIL DAN PEMBAHASAN}

\section{Fluktuasi Harga Sayuran di Pasar}

Fluktuasi harga yang relatif tinggi pada komoditas sayuran di Kota Bogor berkisar antara 5-20\%. Perbedaan ini diduga sebagai akibat dari kegagalan petani sehingga pasokan ke pasar berkurang dan pedagang sayuran dalam mengatur volume pasokannya sesuai dengan kebutuhan konsumen. Hasil penelitian menunjukkan bahwa:
1. Produksi sayuran cenderung terkonsentrasi di daerah-daerah tertentu saja, misalnya sekitar $90 \%$ produksi bawang merah yang dijual di Bogor didatangkan dari petani di Kabupaten Brebes Jawa Tengah. Kentang sebagian besar didatangkan dari daerah Pangalengan Kabupaten Bandung Barat. Sedangkan tomat didatangkan dari petani dari daerah dataran tinggi sekitar Kota Bogor, yaitu Kabupaten Sukabumi (Goalpara), Cisarua dan Cipanas. Komoditi sayuran daun yaitu bayam didatangkan dari daerah Bojong Piceung, Parung dan Ciampea Kabupaten Bogor. Struktur produksi demikian tidak kondusif bagi stabilitas harga karena jika terjadi anomali produksi (misalnya, gagal panen akibat hama atau lonjakan produksi akibat pengaruh iklim) di salah satu daerah sentra produksi, maka akan berpengaruh besar terhadap keseimbangan pasar secara keseluruhan.

2. Permintaan komoditas sayuran umumnya sangat sensitif terhadap perubahan kesegaran produk. Sementara itu komoditas sayuran umumnya relatif cepat busuk sehingga petani dan pedagang tidak 
mampu menahan penjualannya terlalu lama dalam rangka mengatur volume pasokan yang sesuai dengan kebutuhan pasar, karena hal itu dapat berdampak pada penurunan harga jual yang disebabkan oleh penurunan kesegaran produk. Konsekuensinya adalah pengaturan volume pasokan yang disesuaikan dengan kebutuhan konsumen tidak mudah dilakukan karena setelah dipanen petani cenderung segera menjual hasil panennya agar sayuran yang dipasarkan masih dalam keadaan segar. Kondisi ini yang sulit untuk dilakukan petani mengingat belum adanya integrasi beberapa komponen dalam kegiatan rantai pasok seperti kegiatan perencanaan yang akan mengoordinasikan jenis dan jumlah kebutuhan sayuran tidak dilakukan oleh petani.

3. Untuk dapat mengatur volume pasokan yang sesuai dengan kebutuhan konsumen maka dilakukan proses ekualisasi. Pada sayuran kentang dan bawang merah, proses ekualisasi dilakukan di pasar induk Kemang, sedangkan sayuran daun dilakukan oleh pedagang besar di pasar, namun masih kurang efektif pelaksanaannya. Proses ekualisasi ini sangat diperlukan untuk menstabilisasi harga dan menjaga ketersediaan pasokan. Ekualisasi agar berhasil dibutuhkan sarana penyimpanan yang mampu mempertahankan kesegaran produk secara efisien. Namun ketersediaan sarana penyimpanan tersebut umumnya relatif terbatas akibat kebutuhan investasi yang cukup besar sedangkan teknologi penyimpanan sederhana yang dapat diterapkan oleh petani sangat terbatas dan menjadi kendala di pedagang pasar induk. Sehingga proses penyimpanan dilakukan dengan sangat sederhana.

\section{Harga Barang}

Barang-barang yang dijual di pasar tradisional dan pasar modern memiliki perbedaan harga yang cukup signifikan. Harga suatu barang di pasar tradisional bahkan bisa sepertiga dari harga barang yang sama yang dijual di supermarket, terutama untuk produk-produk segar seperti sayur-mayur serta bumbu-bumbu dapur seperti bawang merah, bawang putih, jahe, lengkuas, merica, cabai merah, cabai rawit, dan lain sebagainya. 


\section{Identifikasi Rantai Pasok}

1. Rantai Pasok Bayam

Terdapat 3 rantai pasok dalam pemasaran bayam, yaitu:

- Petani-Konsumen

- Petani - Tengkulak - Pasar Bogor/ Warung Jambu - Konsumen

- Petani - Tengkulak - Pasar Bogor/ Warung Jambu - Retailer Konsumen

2. Rantai Pasok Tomat

Terdapat 5 rantai pasok dalam pemasaran tomat, yaitu:

- Petani - Konsumen

- Petani - Tengkulak - Pasar Bogor/ Warung Jambu - Konsumen

- Petani - Tengkulak - Pasar Bogor/ Warung Jambu - Retailer Konsumen

- Petani - Tengkulak - Pasar Induk Kemang - Retailer - Konsumen
- Petani - Tengkulak - Pasar Induk Kemang - Pasar Bogor/Warung Jambu - Retailer - Konsumen

3. Rantai Pasok Kentang

Terdapat 3 rantai pasok dalam pemasaran kentang, yaitu:

- Petani - Tengkulak - Pasar Induk Kemang - Pasar Bogor/Warung Jambu - Konsumen

- Petani - Tengkulak - Pasar Induk Kemang - Retailer - Konsumen

- Petani - Tengkulak - Pasar Induk Kemang - Pasar Bogor/Warung Jambu - Retailer - Konsumen

\section{Perhitungan Nilai Margin dan Farmer Share}

Sebaran nilai margin dan farmer share untuk komoditas bayam, tomat dan kentang dapat dilihat pada Tabel 1.

Tabel 1. Perhitungan Nilai Margin dan Farmershare

\begin{tabular}{clccccc}
\hline No & Komoditas & $\begin{array}{c}\text { Rata-rata Total } \\
\text { Margin (Rp) }\end{array}$ & $\begin{array}{c}\text { Rata-rata } \\
\text { Farmershare }(\boldsymbol{\%})\end{array}$ & Satuan & Pf (Rp) & Pn (Rp) \\
\hline 1 & Bayam & 864,6 & 17,2 & Ikat & 170 & 986,4 \\
\hline 2 & Tomat & $6.003,5$ & 29,4 & $\mathrm{Kg}$ & 2.500 & $8.503,5$ \\
\hline 3 & Kentang & 4.642 & 68,3 & $\mathrm{Kg}$ & 10.000 & $14.642,6$ \\
\hline
\end{tabular}

Berdasarkan Tabel 1 diketahui bahwa farmer share terkecil pada komoditas bayam dan terbesar pada komoditas kentang. Nilai margin terkecil pada komoditas bayam dan paling besar pada komoditas tomat. Dengan demikian, maka petani kentang memperoleh bagian harga yang paling besar dibanding komoditas lainnya, hal ini karena terjadi proses tawar menawar antara petani dengan tengkulak pengumpul. Apabila tidak terjadi 
kesepakatan harga, maka petani dapat menawarkannya kepada tengkulak lainnya untuk memperoleh kesempatan dalam menjual hasil panennya dengan harga yang lebih mahal. Komoditi kentang juga tidak serta merta harus dipanen pada saatnya, kentang dapat ditunda panennya di lahan sampai sekitar sepuluh hari, sehingga petani dapat berkesempatan untuk mencari informasi harga yang lebih tinggi dari yang telah ditawarkan para tengkulak.

\section{Sistem Rantai Pasok Sayuran}

Alur distribusi sayuran untuk jenis bayam tomat dan kentang di pasar tradisional dapat dilihat pada Tabel 2.

Tabel 2. Sistem Rantai Pasok Sayuran di Pasar Tradisional Tahun 2017

\begin{tabular}{|c|c|c|c|c|}
\hline No. & Aspek & \multicolumn{3}{|c|}{ Jumlah Pedagang } \\
\hline \multirow[t]{2}{*}{1} & \multirow[t]{2}{*}{ Perencanaan pengiriman } & Direncanakan & Tidak Di & akan \\
\hline & & $2(18 \%)$ & 9 & \\
\hline \multirow[t]{3}{*}{2} & \multirow[t]{3}{*}{ Sistem pembayaran } & Antar Penjual & \multicolumn{2}{|c|}{ Antar Pembeli } \\
\hline & & Tunda Bayar $\quad 11(100 \%)$ & Tunda Bayar & 0 \\
\hline & & Tunai & Tunai & $11(100 \%)$ \\
\hline \multirow[t]{2}{*}{3} & \multirow{2}{*}{$\begin{array}{l}\text { Komoditi tidak terjual } \\
\text { (sisa) }\end{array}$} & Ada Sisa & \multicolumn{2}{|c|}{ Habis } \\
\hline & & $11(100 \%)$ & \multicolumn{2}{|c|}{0} \\
\hline \multirow[t]{2}{*}{4} & \multirow{2}{*}{$\begin{array}{l}\text { Ada tidaknya data base } \\
\text { pelanggan }\end{array}$} & Ada & \multicolumn{2}{|c|}{ Tidak Ada } \\
\hline & & 0 & 11 & \\
\hline
\end{tabular}

Berdasarkan Tabel 2 dapat diketahui bahwa proses distribusi sayuran ke pasar tradisional belum ada proses perencanaan. Sistem pembayaran berbeda antara pedagang eceran dengan pembeli dibayar tunai, tetapi antar penjual/ pedagang semuanya dengan tunda bayar. Semua pedagang pernah mengalami sisa sayuran yang diperdagangkan dengan demikian terdapat ketidaksesuaian antara kebutuhan konsumen dengan yang dijual pedagang. Serta tidak ada data base pelanggan.

\section{KESIMPULAN DAN SARAN}

\section{Kesimpulan}

1. Pemetaan pemasaran menunjukkan bahwa produsen sayuran daun berasal dari lokasi lahan petani yang berdekatan dengan kota Bogor. Sedangkan sayuran yang relatif lebih tahan lama yaitu kentang dan bawang merah berasal dari petani pada lokasi yang lebih jauh dari pada lokasi sayuran daun.

2. Semua jenis sayuran yang diteliti dalam distribusinya melalui proses ekualisasi. Petani kentang lebih berkesempatan memperoleh bagian 
harga yang diterima dibanding komoditi lainnya.

3. Performance rantai pasok sayuran tradisional belum terintegrasi keterkaitan erat antara keinginan konsumen dengan produsen/petani, baik dalam perencanaan (Plan), pengadaan (source), produksi (make), distribusi (Deliver) dan pengembalian (Return) serta tindakan (Enable).

4. Belum optimalnya performa/kinerja rantai pasok sayuran di pasar tradisional ditinjau dari aspek reliabilitas, responsivitas, fleksibilitas, biaya dan manajemen aset rantai pasok.

\section{Saran}

1. Petani sayuran daun memfokuskan pada konsumen akhir yang membeli dalam partai besar diantaranya ke konsumen hotel, restoran dan kantin atau warung makan yang langsung mengkonsumsi sayuran yang dihasilkan.

2. Dibentuknya sistem informasi dengan memanfaatkan aplikasi sistem informasi berbasis android yang menghubungkan petani dengan konsumen akhir atau retail.

3. Kesepakatan harga dan jumlah dalam produksi dan distribusi sehingga menguntungkan bagi petani maupun pedagang. Kesepakatan dituangkan dalam perjanjian kontrak jual beli antara petani dan pedagang.

\section{DAFTAR PUSTAKA}

Adiyoga, W. 2010. Perkembangan Rantai Pasok Supermarket: Implikasinya terhadap Partisipan serta Struktur Rantai Pasokan Pasar Tradisional. http://www.scribd.com/doc/249303 13/an-Rantai-PasokanSupermarket\#scribd

Andri, K. B. 2015. Analisa Rantai Pasok Agribisnis Hortikultura Wilayah Perbatasan Indonesia dan Malaysia di Nunukan Tawau. http://dipertanaknunukan.blogspot.c om. Diakses 4 Januari 2015.

Chain Council. 2006. SCOR version 9.0 Overview. $\mathrm{SCC}$, Washington DC.

Dirjen Hortikultura Kementan. 2012. Cetak Biru Pengembangan Hortikultura Tahun 2011-2025. Direktorat Jenderal Hortikultura Kementerian Pertanian RI. Jakarta.

Hasan, A. 2013. Marketing dan Kasuskasus Pilihan. CAPS (Center for Academic Publishing Service). Yogyakarta.

Miftah, H. dan A. Syarbaini. 2014. Model Pemberdayaan Petani Ubikayu melalui Pola Sistem Agribisnis Terintegrasi di Kabupaten Sukabumi Provinsi Jawa Barat. SEPA Jurnal Sosial Ekonomi Pertanian dan Agribisnis 10(2): 298-304.

Oktapiana, A. dan T. Perdana. 2014. Rantai Pasok dalam Klaster Agribisnis Sayuran di Pangalengan untuk Pasar Terstruktur. Jurnal Agric. Science. 1(4): 313-320. 
Saptana. 2014. SCM yang berpihak pada Petani dan Nelayan. Prosiding Konferensi Nasional XVII dan Kongres XVI Tahun 2014. Perhimpunan Ekonomi Pertanian Indonesia (PERHEPI) IPB International Convention Centre (IICC) pada Kamis-Jumat/28-29 Agustus 2014. Bogor.
Supriatna A. dan B. Drajat. 2011. Pola Kemitraan dalam Peningkatan Efisaiensi Pemasaran. Prosiding Seminar Nasional: Petani dan Pembangunan Pertanian, 12 Oktober 2011. Pusat Sosial Ekonomi dan Kebijakan Pertanian, Badan Penelitian dan Pengembangan Pertanian, Kementerian Pertanian. Bogor. 